\title{
Design and Implementation of Training Standards for Outstanding Talents under the Background of "Educational Informatization"
}

\author{
SUN Jie ${ }^{1, a}$, Zhang Xiaoqian ${ }^{2, b}$ \\ ${ }^{1}$ Tianjin University of Science and Technology China, Tianjin, Binhai New Area \\ ${ }^{2}$ Tianjin University of Science and Technology China, Tianjin, Binhai New Area
}

\begin{abstract}
Educational informatization means that colleges and universities use abundant information resources to help their teaching work. On April 13, 2018, the Ministry of Education officially released the Action Plan for Educational Informatization 2.0. Through the analysis of the training of outstanding talents under the background of "education informatization" in China, this paper finds out the problems faced by the training of outstanding talents in China, namely: in the context of internationalization and informatization, the gap between the undergraduate graduates and the international standards and industry needs is large, lack of exploration and innovation; the professional education activities in college personnel training need to be improved in terms of professionalism and lack of systematicness and flexibility. Talent training mode is lack of diversity and adaptability; and the ideological and moral education in the process of talent cultivation is insufficient. In addition, this paper further conclude the importance and urgency of building great talent training standard, from ideological and ethical standards, professional knowledge and ability, innovation ability three aspects to establish excellent talent training standards, and that excellence in the talent training standards by school learning and create "'" excellence initiative" summer/winter camp "to concrete practice.
\end{abstract}

\section{The introduction}

The present age is the information age, mastering the information nowadays the important goal of the talent cultivation. On the one hand, improving information literacy is incorporated into the educational goal to cultivate talents to adapt to the information society. On the other hand, information technology is applied effectively to teaching management and scientific research, and attention is paid to the development and utilization of educational information resources ${ }^{[1]}$.

Steadily along with the advancement of socialist modernization, our country for high caliber individuals with higher demands, cultivation of excellent talents also pay more attention to, talents especially outstanding talents in colleges and universities is the future of China's advanced talents reserve, is the future innovation ability in our country and even around the main force of the future development of science and technology level. Therefore, under the background of educational informatization, what is the outstanding talents, what is the new development of the training standard of outstanding talents, and how to implement the standard of outstanding talents are all urgent to be demonstrated.

But different specialties, teaching quality in colleges and universities, and for what kind of person is the excellent talents, talents' cultivation standard of excellence is what there is no uniform definition, which makes understanding of excellent talents from all walks of life are different, affected the outstanding talented person's raise and the implementation of the excellence initiative and subsequent development, therefore, this article try to outstanding talents under the background of education informatization defining the connotation and training standards.

\section{The current situation of the cultivation of outstanding talents in universities in China}

\subsection{The current mode of cultivating outstanding talents in colleges and universities in China}

So far, more than 300 universities in China have joined the Excellence Initiative in batches. Among colleges and universities, the most common way to cultivate outstanding talents is to set up "experimental class", "excellent class", "excellent school", etc., to select the students with the highest comprehensive performance in their major to another class or school, or increase the curriculum arrangement, or increase off-campus practice, or both. This article only lists the implementation of the following colleges and universities, intended to roughly explain the basic situation of the training of outstanding talents in colleges and universities.

For example, Zhejiang University has designed outstanding talent training programs for different majors, but basically adopts the form of administrative classes for

\footnotetext{
aEmail: jerson@tust.com

bE-mail: 18830732195@163.com
} 
students who participate in the program of excellence. Shanghai Jiao Tong University has established the special class of excellence. Although the training mode of each major has its own characteristics, the common point is that students are selected to enter the special class of excellence for the training of outstanding talents. In Jiangsu University, the College of Excellence was established to coordinate the talent cultivation of the "Program for Excellence", and 50 freshmen were selected from relevant colleges to form the "Class of Excellence". In 2017, the "Kingsoft Talents Plan" was implemented. Every year, about 30 students were selected from the freshmen to form the "Jinshan Talents Class". In a similar way, Nanchang University has set up school-enterprise cooperative experimental classes and excellent classes, such as Jiangling Experimental Class, Hangtian Experimental Class, Dongruan Experimental Class, ZTE Experimental Class, Geely Automobile Experimental Class, Jiangyang Experimental Class, etc. The situation of other colleges and universities is similar. Most of them set up a variety of characteristic classes to select top students based on their academic performance to form characteristic classes to implement the "Excellence Plan", which combines professional ability with practical ability and innovation ability, and cultivates many outstanding professionals for our country.

\subsection{Problems in the process of cultivating outstanding talents in colleges and universities}

With the in-depth implementation of the "Excellence Plan", there are more and more discussions on the cultivation of outstanding talents from all walks of life. Problems in the cultivation of outstanding talents gradually appear: the political standing of the cultivated talents is not high enough, and the ideological and moral education in the process of talent cultivation is insufficient; in the context of internationalization and information technology, there is a big gap between undergraduate students and international standards and industry needs, and they are lack of exploration and innovation. The specialization of education activities in college talents training needs to be further improved, and it is not systematic and flexible enough. Talent training mode is lack of diversity and adaptability ${ }^{[2]}$.

First, the political position of talents is not high enough, and the ideological and moral education is insufficient in the process of talent training. Lack of ideological and moral education mainly embodies the following aspects: first, has long been problems of urban and rural talent proportion imbalance, spontaneously in the role of market regulation, the college students, especially the excellent college students principal place of employment after graduation is north to Guangzhou, and other first-tier cities, in the city at all levels of employment intention, employment intention from the cities to the countryside to (as shown in figure 1), and walked out rural college students rarely choose to go back to the countryside, this leads to smaller cities and rural talent shortage. And our country is in the construction of a well-off society in an all-round way to realize a crucial and critical period of socialist modernization, the gap between us and a well-off society in an all-round way from talent is the talent gap between rural and urban problems, therefore, giving play to the role of non-economic means and narrow the gap between urban and rural people, make the distribution curve under the market spontaneous adjustment of talents tend to be more vertical (figure 2) is the key problems of the construction of the talents. Secondly, internationally, similar to the domestic talent distribution curve, the talent distribution is decreasing from developed countries to developing countries. Especially in today's Internet era environment, materialism, individualism and other bad ideas of the western world into the minds of students, so that students' patriotic feelings reduced. According to the 2019 Employment Report of Chinese College Students released by MyCOS Research Institute, from 2014 to 2018 , the rate of Chinese undergraduates studying abroad after graduation has increased year after year. According to statistics from the Ministry of Education, from 1978 to the end of 2018, among the 4.323,200 students who had completed their studies, 671,800 chose to stay abroad, accounting for more than 10 percent of the total number of students studying abroad. From the perspective of noneconomic factors, the above problems are caused by the lack of political standing, ideological and moral education, and the lack of social responsibility and national sense of belonging among Chinese college students. However, we clearly know that the purpose of cultivating talents is to retain talents and use them for the country. This paper believes that retaining talents and using good people is one of the keys to the success of the implementation of Excellence Program. The key to talent training lies in colleges and universities, and the key to solving the problem of brain drain also lies in college education.

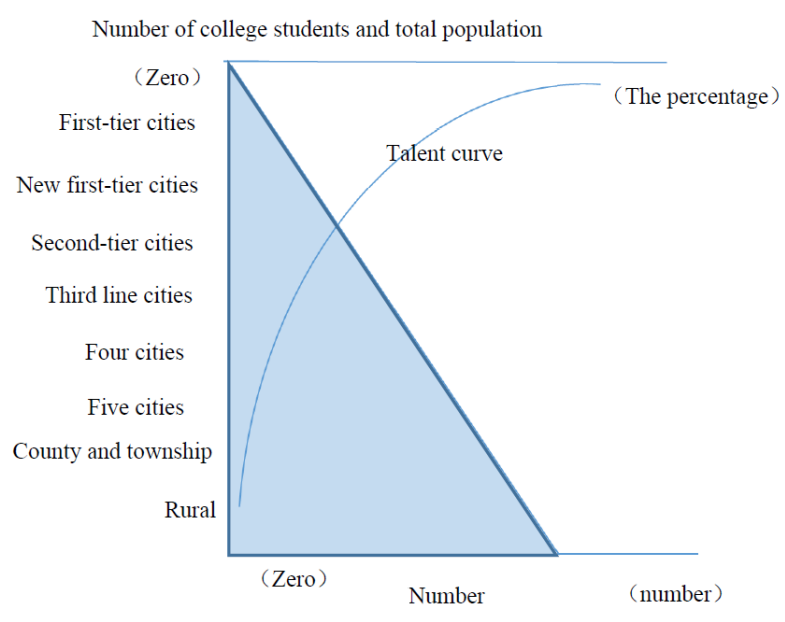

Fig 1. Ratio of types and talents in each region 


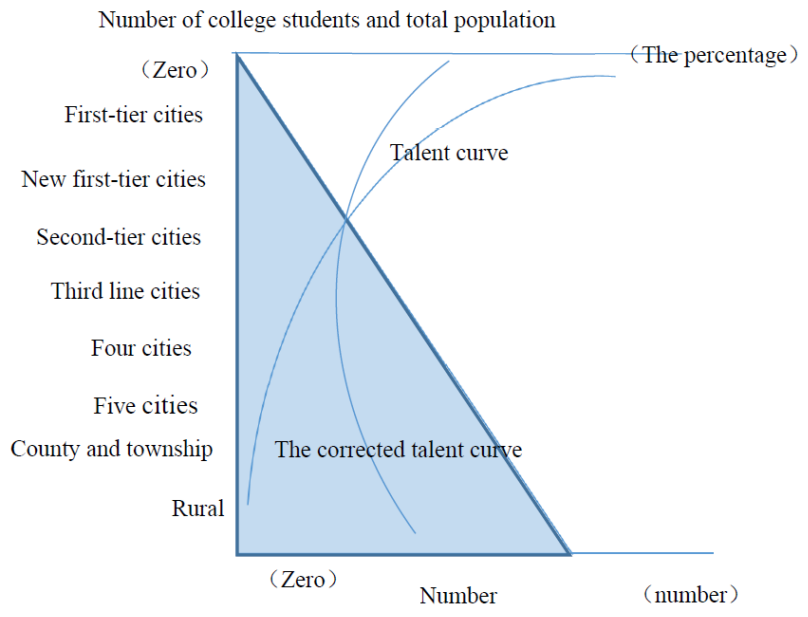

Fig 2. Revised map of the number of types and talent ratio in each region

Second, in the context of internationalization and information technology, there is a certain gap between undergraduates and international standards and social needs, and the innovation and entrepreneurship ability needs to be improved. This is mainly reflected in the low degree of participation of Chinese college students in innovation and entrepreneurship practice, less social practice activities, and in terms of academic achievements, the repetitive simple academic achievements are far more than the original research achievements. In addition, due to historical and social reasons, there is a certain gap between the training standards of college students in China and the international standards and social needs, and the talents cultivated can not fully meet the international and domestic talent needs.

Third, the professional education activities in the training of outstanding talents in universities need to be improved, and the system and flexibility are insufficient. At present, the curriculum Settings of some colleges and universities are not scientific enough, and many professional curriculum Settings tend to be large and complete, while ignoring the professionalism. As a result, many professional courses have insufficient class hours and inadequate professional practice after class, and students will no longer have follow-up study after the completion of a course, which greatly reduces the effect of professional education. In addition, there are also problems in the system and flexibility of talent training, the balance between the system and flexibility of talent training has not been reached.

Fourth, the training mode of outstanding talents lacks diversity and adaptability. In China is the world's largest developing country, in the economic form, economic system in such aspects as industrial structure, regional distribution and diversity and complexity, this feature requires personnel must have the diversity and adaptability, but at present our country most of the colleges and universities to set up various forms of "experimental class" for outstanding talents, cultivating mode is relatively single, adaptability is not strong, the personnel training mode of cannot fully meet the demand, talent exists structural imbalances, talent market supply and demand do not match.
In conclusion, how to improve the quality of talent training, promote the coordinated development of cultivating talented person, reduce the contradiction between supply and demand of market, improve the students' innovation ability is the key to the reform of undergraduate talent training in our country, we need to carefully consider the talent training target, establish and improve the talent training standards, under the guidance of "excellence initiative" to do a good job of talent training. Therefore, in the present and in the future for a long period of time, clear definition and training standards of outstanding talents, is now the implementation and further implementation of the "excellence program" of the key issues.

\section{The connotation and quality characteristics of outstanding talents under the background of educational informatization}

According to the above problems found in the process of cultivating outstanding talents and the current construction needs of our country, this paper defines the connotation and quality characteristics of outstanding talents.

\subsection{The interpretation of the connotation of outstanding talents}

In 2010, the requirement of the Ministry of Education for the cultivation of excellent engineers is to cultivate highquality and various types of engineering and technical talents with strong innovation ability and meeting the needs of economic and social development ${ }^{[3]}$. After that, Chen Baosheng, secretary of the Party Leadership Group and minister of the Ministry of Education, proposed "four regressions" ---- return to common sense, return to duty, return to the original aspiration and return to dreams ${ }^{[4]}$; In 2018, the Ministry of Education put forward in the Opinions on Accelerating the Construction of High-level Undergraduate Education and Comprehensibly Improving the Ability of Talents Training that we should take improving the ability of talents training as the core to carry out talent construction and train socialist builders and successors with all-round development of morality, intelligence, physique, aesthetics and labor. Through the proposal of a series of national policies and requirements, it can be seen that the original intention of the Excellence Program is not only to cultivate outstanding professional talents, but also to cultivate outstanding "successors" with strong ideas, top professional skills, innovation and entrepreneurship and other abilities. To be specific, for example, for science and engineering majors, it is to cultivate craftsman spirit; for liberal arts majors, it is to cultivate innovative and entrepreneurial talents; and for arts majors, it is to cultivate masters. In general, it is to teach students in accordance with their aptitude and cultivate talents with distinctive features and key points. 


\subsection{Quality characteristics of outstanding talents under the background of educational informatization}

In the information age, to cultivate outstanding talents, we not only need to train students to love their majors, but also require schools to cultivate outstanding talents who can fully collect, organize, excavate and use information.

\subsubsection{Ability to fully collect, mine and use information}

This is the basis for students to maintain their excellence and make continuous progress in the information age. For students, they need to be able to skillfully use network information means to complete theoretical study and practical research. In the process of theoretical learning, students can process all forms of information they have received comprehensively and use them for them own use. In the study of practice, to be able to skillfully to carry on the literature search, understand the latest developments in the academic, in the practice of emergency can use information network also need to communicate and exchange with the outside world through the network, and can in practice through various means to analyze the results of informatization, so as to find out the cause of the failure, summarizes the successful experience.

\subsubsection{Have a strong mind}

Excellent thinking is the ideological basis of cultivating outstanding talents. First of all, it is necessary to cultivate the pattern view of students. Outstanding talents are the leading talents of China's future construction, and they must have a high enough political stand and ideological pattern. Outstanding talents adhere to the national spirit with patriotism as the core and the spirit of The Times with reform and innovation as the core, adhere to the core socialist values, adhere to the "Four Consciousness, Four Confidence and Two Protections", to make contributions to the country as the highest ideological pursuit, to serve the country and the people as their own duty. Secondly, students need to be able to persevere in the face of difficulties, indomitable spirit, can be leisurely in the face of difficulties. Third, the student must have a strong sense of social responsibility, small said, including the people skills to establish good relationships with others, in life there is a clear rule of life, a positive attitude to life, to have a clear goal in study and work, positive attitude, good at working together with others, assiduous sureness; Generally speaking, it is to create social wealth, promote social progress and promote human development.

Strong thinking is also the key to retaining talent. Students develop stage is not only the key period of students professional skills upgrading, and pattern of students' view and critical period of ideological and moral quality, lets the student in the study period by adopting a good ideological and moral quality, stimulate their strong spirit of patriotism, and for the people, for the social service consciousness, can let more outstanding talents to bolstering areas involved in construction, let more overseas talent to voluntary in construction of the motherland, contribute to the motherland.

\subsubsection{Excellent comprehensive quality and professional quality}

Here comprehensive quality includes basic ideological and moral quality, professional ability, humanities and social science, natural science, psychology, physical quality and so on. Comprehensive quality is a qualified undergraduate graduates must have the quality.

Excellent professional quality is the basic requirement of outstanding talents. The so-called professional quality mainly refers to the comprehensive professional basic theoretical knowledge, professional skills, professional research, professional practice ability and the ability to ensure that the above ability can be used to the relevant political, economic, legal and social environment analysis and response ability.

\subsubsection{Excellent ability of innovation and entrepreneurship}

Excellent ability of innovation and entrepreneurship is the goal of cultivating outstanding talents. Today's society changes with each passing day, and all kinds of new things emerge in an endless stream. Moreover, due to the development of various science and technology such as economic globalization and the Internet, the world is increasingly connected and international competition is increasingly fierce, which puts forward higher requirements for talent cultivation. In such a background, the outstanding talented person to be able to with combining information and innovation ability of innovation, to analyze and adapt to the rapid changes in the economic, political, social, international environment and market demand, meet and create diversified market demand and supply, for facing the competition risk and the social demand constantly proposed solutions of creative, innovative ideas, methods and strategies, and be able to put into practice, achieve the expected result. Excellent talents, on the other hand, needs to have the remarkable ability, namely can find or create a new field, to understand and create new products, new markets, new process, new raw materials, a new method of organization existing technology and other new things, and be able to use various methods to utilize and develop these new things, and produce various kinds of new results ${ }^{[5]}$.

\section{Training standards for outstanding talents}

\subsection{The importance of establishing standards for training outstanding talents}

In the process of talent training, talent training standard is the basis for establishing talent training program, implementing talent training process and finally achieving talent training goal. In 2018, the Ministry of Education issued the National Standard for the Quality of Undergraduate Professional Education in Colleges and 
Universities (hereinafter referred to as the Standard). Before that, all sectors of society mainly stipulated the cultivation of students based on educational purposes and objectives. However, both educational objectives and objectives are relatively broad, lack of accurate positioning of talent training, and it is not easy to implement. Therefore, in order to regulate talent training, it is necessary to establish scientific standards for talent training.

In the Standard, talents training standards for 92 undergraduate majors and 587 majors have been formulated. This provides a direction for the training of talents in colleges and universities. However, the Ministry of Education also clearly points out that this standard is the standard to protect the foundation, the bottom line and the qualification. Obviously, this basic standard cannot meet the needs of the training of outstanding talents. The training standard of outstanding talents must be higher than the requirements of this standard, and it is absolutely not enough to train outstanding talents according to the national standard. The training standard of outstanding talents must be based on the national standard and higher than the national standard. Therefore, it is necessary to establish a scientific standard for the cultivation of outstanding talents to promote and regulate the cultivation of outstanding talents in our country.

\subsection{Training standards for outstanding talents}

According to the quality characteristics of outstanding talents, this paper divides the training standards of outstanding talents into three aspects. Namely: ideological and moral standards, professional knowledge ability standards, innovation and entrepreneurship ability standards.

\subsubsection{Informatization standards}

In this standard, the first is the ability to find information. Students must have a keen insight and understanding when dealing with complex information, and be able to find out the information they need from the complex information.

Secondly, the ability to use information requires students to make full use of the information they have mastered and constantly dig out the connotation and function of data information.

\subsubsection{Political structure and ideological and moral standards}

Political pattern and ideological and moral standards are the basic requirements for the training of outstanding talents. Having a high enough political pattern view and excellent ideological and moral level is the basic quality that outstanding talents must have. It mainly includes social responsibility and professional ethics. To be specific, according to the standard requirements of social responsibility, universities should adhere to the core socialist values, strengthen patriotism education, and guide students to build up the consciousness of serving the country and the people in the training of outstanding talents according to the characteristics of "strong thinking". In the standard requirements of personal quality, outstanding talents are required to have higher personal quality characteristics. Reverse quotient is the essential personal quality of outstanding talents. On this basis, students must have the spirit of constantly pursuing personal growth, insisting on noble personal integrity and improving their own innovation ability.

\subsubsection{Professional knowledge and ability standards}

Professional knowledge standards mainly refer to the professional knowledge that students have learned in school. Professional knowledge standard based on the characteristics of the remarkable talent "professional elite", for colleges and universities, in the process of outstanding talent training should pay attention to the establishment of the professional training system, constantly adjust the teaching plan and program of keeping pace with The Times, constantly introduce the latest research achievements of relevant professional talent training scheme, continuously carry out academic research and academic exchange activities, set up benign campus offcampus combination of academic communication system, provides the foundation for students to improve professional quality. For students, they should start from their own interests, choose their own major, and continue to work in their own professional field. In this standard requirements, mainly divided into six standard points, namely: professional results, professional knowledge and skills certificates obtained, professional field competition awards, professional teacher evaluation, graduation thesis, graduation practice, etc..

To be specific, first, professional scores reflect students' mastery of professional knowledge, and the requirements for professional scores ensure the professional knowledge foundation of outstanding talents. This paper believes that the professional scores of students participating in the training of outstanding talents must reach $15 \%$ of the ranking of their major. Secondly, professional teachers' evaluation of students is the recognition degree of teachers' mastery of students' professional knowledge and ability, which can be evaluated according to four levels of good or bad. Third, the professional knowledge and skills certificate is the embodiment of the students' professional knowledge and skills recognized by the country. The Chinese government and the authoritative professional associations or research institutes have explained the professional certificates that the students need to obtain. The number and quality of the professional certificates that the students obtain during the school period is the scoring basis of this standard. Fourth, the award of professional field competition is the embodiment of students' ability to apply professional knowledge to practice. Students' ability under this standard can be evaluated according to whether the award belongs to the provincial or national level and the award ranking. Fifth, the situation of graduation thesis reflects the school's final evaluation of students' knowledge mastery, which can be assessed according to the 
requirements of the Ministry of Education for undergraduate students' graduation thesis; Sixth, the situation of graduation practice reflects the students' comprehensive ability of applying theory to practice. At present, China's colleges and universities have set requirements for graduation practice. The evaluation of this standard can be determined according to the requirements of graduation practice of colleges and universities.

\subsubsection{Standards for innovation and entrepreneurship ability}

At present, the country pays more and more attention to the innovation and entrepreneurship ability of college students, and many scholars have studied the standards of innovation and entrepreneurship ability of college students. For example, on the basis of absorbing previous studies, Shen Ming established the evaluation index system of college students' innovation and entrepreneurship ability based on rough set theory, including four first-level indicators including innovation and entrepreneurship environment, innovation and entrepreneurship education, innovation and entrepreneurship practice, and innovation and entrepreneurship achievement, and 12 second-level indicators ${ }^{[6]}$. Colleagues from the perspective of empirical using exploratory factor analysis method to establish the university students' innovative undertaking ability influence factor system, including the pioneering research and development ability, innovation, knowledge innovation ability, practice ability innovative undertaking a grade three main factors, development environment, research and development, intellectual environment, environmental knowledge, practice, practice results six class B, such as the main factors and factors of 17 children $^{[7]}$. Based on the innovation ability in the standard draws on the results, on the basis of outstanding talent "has the outstanding creative ability", the characteristics of colleges and universities as the subjects of entrepreneurial innovation education have important responsibility for outstanding talents, for colleges and universities should be four aspects: one is creative consciousness cultivation, namely the enlightenment and stimulate students' innovation consciousness and entrepreneurial spirit, innovative entrepreneurial activity, a professor at the required basic knowledge; Second, the improvement of innovation and entrepreneurship ability, that is, the cultivation of students' innovation and entrepreneurship qualities, so that students have the necessary innovation and entrepreneurship ability; Third, the awareness of innovation and entrepreneurship environment, that is, let students understand the current entrepreneurial environment, grasp innovation and entrepreneurship opportunities, flexible use of innovation and innovation strategies and skills, to resist the risk of innovation and entrepreneurship; Fourth, practice simulation. Innovation and entrepreneurship simulation activities are introduced in the teaching process, so that students can personally experience the problems that may be encountered in innovation and entrepreneurship activities.

\section{The implementation of the training standards for outstanding talents}

Specifically, the implementation of excellence standards can be achieved through school study and the "excellence program summer/winter camp".

First of all, in the learning process, make full use of education informatization technology, using a variety of internal and external information sharing platform platform and network course platform, causes the student to receive information to a great extent, the study knowledge, can achieve the basic ideological and moral quality, comprehensive quality and professional knowledge, let the students have the ability to learn and gain the ability to learn, on this basis, through the school organization all kinds of scientific research, innovation, entrepreneurship and the realization of tutoring students innovation ability of the business.

Secondly, through the "excellence in summer/winter camp" students further enhance students' ideological and moral level, enhance personal qualities, and can pass the "excellence in summer/winter camp" get higher rates of innovation ability training, get stronger practical ability, through comprehensive training and development, is the student to obtain excellent comprehensive quality and personal qualities. Specific implementation methods are as follows:

\section{1 "Excellence Program Summer/Winter Camp" student selection}

Choosing which students to enroll in the Excellence Program is the first step in the implementation of the program and will largely determine the quality of the program implementation. Based on existing practice and research experience, students should enter the Excellence Program for the first time after the end of courses in the first semester of their freshman year, and select students whose overall score in each major is within $15 \%$ (this proportion can be adjusted). This can effectively control the professional quality of the students who enter the Excellence Program, and also prevent the problem of excessive selection of trainers and training sites. In future academic years, the selection of "Excellence Program" students shall also comply with the overall score ranking of the major within $15 \%$. In addition, due to the possibility of changes in scores among students, if a new student enters the program, the new student shall make up for the credits he/she should have obtained in the previous academic year.

For new entrants, how to make up for the credits of the previous academic year can be realized through the following ways. First, the school provides students with online courses, and students can complete the courses in their spare time within a limited period of time and obtain corresponding credits. Secondly, the student should provide the school with the enterprise internship certificate during the previous school year.

This way can make students start to pay attention to their professional learning and professional practice at the beginning of the school under the impetus of the 
competitive consciousness, and reduce the slack study state existing in many undergraduate students.

\section{2 "Project for Excellence" summer/winter camp curriculum}

\subsubsection{Ideological and moral education courses}

The author believes that the ideological and moral education curriculum is the most basic part of the curriculum system of the Excellence Program and should be paid enough attention to by schools.

In view of the ideological and moral education, the author thinks that can refer to the cultivation of the party members' ideological and moral education methods, carry out various kinds of ideological and moral education activities regularly, strengthen the patriotic propaganda, to show the students all aspects of the latest achievements in our country, using the video online and offline meeting, let the students to contribute to the country's people from all walks of life to communicate, to enhance students' national pride and patriotism emotion, strengthen students' sense of social responsibility.

\subsubsection{Innovation ability training courses}

This course is jointly offered by the school and cooperative enterprises and social groups and institutions. The school takes the lead and organizes each partner to form a trainer group. The students take the methods of group cooperation and group cooperation, and gradually cultivate the students' innovation ability through various forms of games or activities.

The advantage of this curriculum is that it maximally integrates the social resources that the school can integrate, provides students with innovative courses provided by trainers from different perspectives, and provides students with comprehensive innovation ability.

\subsubsection{Entrepreneurial ability training courses}

This course offered by the school enterprise cooperation, will differ according to each major feature selection of cooperation enterprise and the corporate sector, by these enterprises and departments provide a variety of entrepreneurial ability training, let the students into the enterprise fieldwork, internships, with ongoing in university career "excellence in summer/winter camp" gain reliable entrepreneurship.

The advantage of this course setting is that students can get more opportunities for continuous internship and investigation in enterprises in four years, which is much more effective than the one-time graduation internship, and the benefits for students will be greater.

\subsection{Selection of collaborators}

The partners here mainly refer to the enterprises, social groups and social institutions that cooperate with the school to participate in the implementation of the Excellence Initiative.

Different universities have different social resources to connect with at different levels. Therefore, for schools, the choice of partners is mainly to choose the most appropriate partners that they can connect with, rather than to pursue the large enterprises, multinational enterprises and large social groups that are widely believed in the society. The school should choose the partners according to the characteristics of the school and the major, and establish the employment plan with the above-mentioned organizations, so that the students can work in the relevant organizations after graduation, so that the school, students and the organization can achieve a win-win situation and common development.

\subsection{Participate in the career arrangement of the graduates with the Excellence Program}

For students who participate in the Excellence Program, after four years of study, the school has two options. First, for those who want to further their studies, the school can recommend them to pursue graduate studies at our school or at another school. Second, for students who want to work, the school can also recommend students to work in relevant cooperative organizations. To solve the problem of students' way out. 


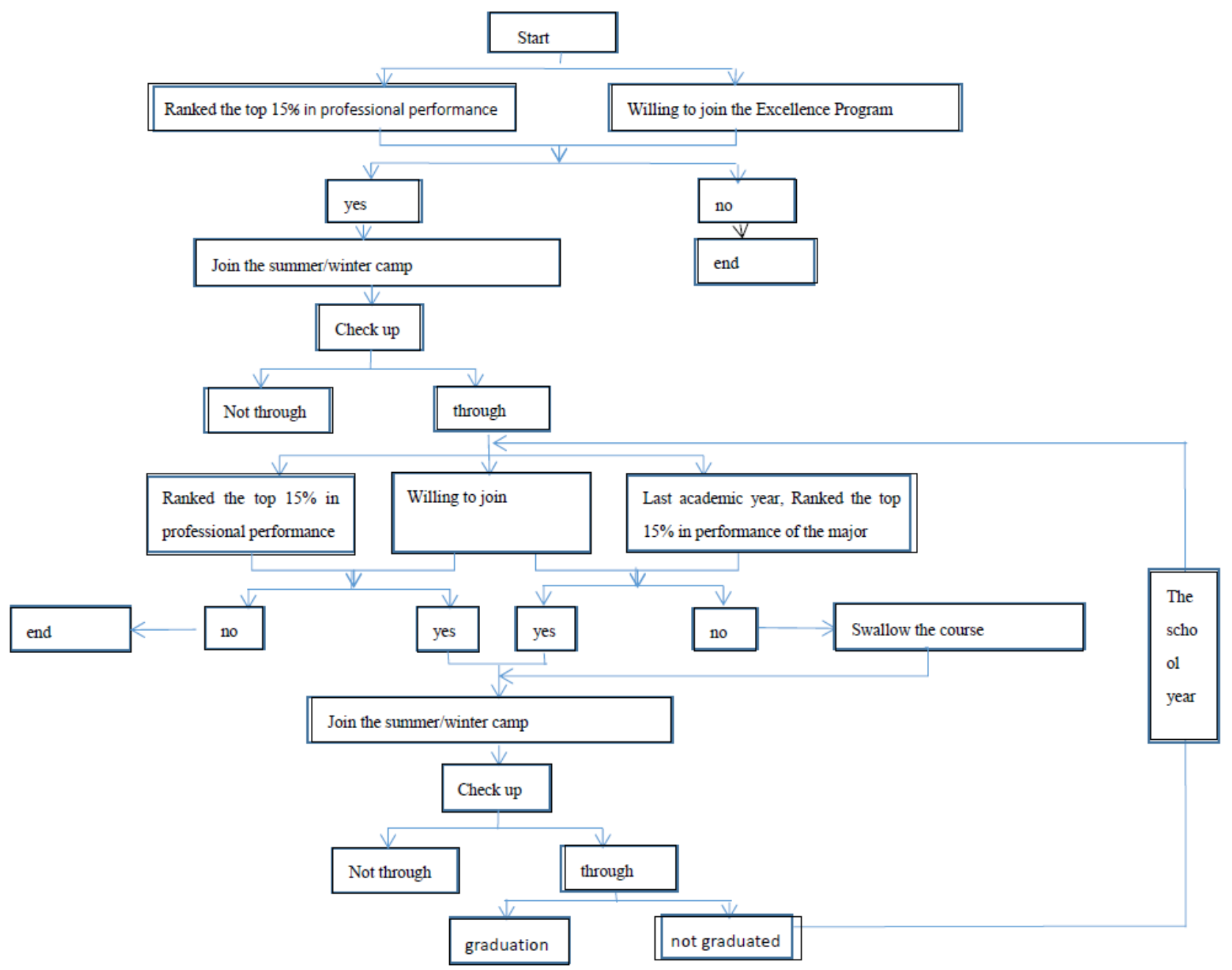

Fig 3. Implementation of the Excellence Initiative

\section{Conclusion}

In general, facing the increasingly complex social environment and the ever-changing information and technology environment, the society has higher and higher requirements on the quantity and quality of talents. This paper thinks that it is of great significance to analyze the training of outstanding talents under the background of educational informatization. The research results of this paper discussed the training standard of outstanding talents in the new situation and new background, and put forward feasible opinions on the training standard of outstanding talents, from the information,. It puts forward the specific requirements of the training standards of outstanding talents from the four aspects of political structure, ideological and moral standards, professional knowledge and ability standards, and innovation and entrepreneurship ability standards, and puts forward preliminary suggestions on how to implement the standards. These suggestions are in line with the requirements of The Times and practical.

\subsection{Deficiencies}

This paper only provides a preliminary training standard suggestion for the cultivation of undergraduate outstanding talents, and the specific implementation methods and existing deficiencies need further study.

First, under the background of educational informatization, whether different professional talents have different requirements and characteristics need to be subdivided.

Second, how to choose cooperative enterprises and organizations in the "Excellence Program" summer and winter camp still needs further study.

Third, the specific curriculum setting of the training of outstanding talents needs to be further discussed.

\subsection{Outlook}

Now, education informatization rapid development momentum, the outstanding talent training has significant effect, but because of various system, the standard construction is not mature, the informationization level is not high, excellent talent training standard has not been perfect and unified, in specific culture is mainly according to the traditional class teaching system of "experimental class" is given priority to, faults, so education is also in actively explored the course of the optimization and reform, is committed to establish a scientific and effective remarkable talent cultivation system. This article is based on excellent talent training standards the urgent problems 
and combined with background of today's education informatization, this article puts forward the excellent talent training standards for the solution to solve the problem of the outstanding talent training standard provides a train of thought, for the cultivation of excellent characteristics are unknown and improper positioning, moral education attaches great importance to the problems such as insufficient to provide a method of problem solving and schools, students, all kinds of cooperation organization can achieve win-win situation.

\section{Reference}

1. Guo Yan. Exploration and Practice of Institutionalization Construction of College Teaching Management under the Background of Educational Informatization [J]. Digital World,2021(03):238-239.

2. Zhang Zijuan, Hao Li, Zeng Huahui, Song Yingying, Zhang Zhenqiang. Discussion on the enhancement of graduate students' innovation practice ability in the information age $[\mathrm{J}]$. China New Communications, 2020,22(24):114-115.

3. Zhang Lirong. Research on the Concept and Realization Strategies of University Research-based Learning [D] East China University of Science and Technology,2017.

4. Wu Yan. The New Situation of Higher Education in the New Era [N]. Guangming Daily, 2017 (013).

5. Jiu Maocuo. Cultivation of Practical Innovative Talents in Economics and Management in Universities in Ethnic Regions [J] Modern Enterprises, 2017 (07).

6. Shen Ming. Research on Evaluation System of College Students' Innovation and Entrepreneurship Capability -- Based on Rough Extension Theory [J] Technological Economics and Management Research. 2019 (07).

7. Li Xuhui, Sun Yan. Research on Key Influencing Factors Identification and Promotion Strategies of College Students' Innovation and Entrepreneurship Ability [J] Education Development Research. 2019 (Z1). 